\title{
An Answer to the Problem of Other Minds
}

\author{
Maria Antonietta Perna
}

The problem of other minds or selves has been alive in philosophy at least since the inception of the Cartesian private theatre model of the mind. According to this model, the mind is a private realm, an inner landscape or theatre, accessible only from the first-person perspective. If the mind and its contents are accessible exclusively from the first-person perspective, then serious doubts arise-at least in the arena of philosophical debate if not in everyday life - as to whether anyone other than oneself has a mind. By contrast, there is no parallel problem concerning the existence of other brains. This state of affairs engenders some undesirable consequences when it comes to discussing the philosophical underpinnings of those scientific approaches which take the mind and consciousness as appropriate candidates for scientific investigation. In short, if the mind and consciousness are private entities and only the brain is open to public scrutiny, it would seem that a science of the mental would need to ask itself the following question: what entitles the scientist to say that what is under investigation (e.g., brain states, behavioral patterns) corresponds to, is the same as, or is a manifestation of another's mental life or consciousness?

Philosophical discussion regarding consciousness and mind has proceeded on two parallel fronts, namely, the front of the mainly Anglo-American or analytical philosophy of mind and that of the so-called Continental tradition. Whether essential differences in the manner in 
which philosophical issues in general—and issues in the philosophy of mind in particular-are tackled justify reference to two distinct fronts remains an open question which will not be pursued in the present paper. However, it is undeniable that some interesting and fruitful philosophical work has gone into a critical appraisal of the conclusions and conceptual apparatuses adopted by philosophers who are usually placed in the Continental tradition, thereby showing how their works can be relevant to the issues with which mainstream analytical philosophy of mind concerns itself. ${ }^{1}$

In this paper I would like to draw attention to what British philosopher of mind, Robert Kirk, has claimed concerning the manner in which Jean-Paul Sartre, a philosopher who is usually placed within the Continental tradition, views the problem of consciousness in relation to other selves. Although Kirk does not engage closely nor extensively with Sartrean existential phenomenology, I think that his claims regarding Sartre's position do require a response. ${ }^{2}$ Firstly, Kirk rightly points to an area of Sartre's philosophy which has been deemed unsatisfactory by Sartre himself, and which Sartrean scholars have by and large found unsuccessful. Secondly, in his recent work Kirk opens up his views to a comparison with Sartre's on a specific philosophical problem. I see this as an apt opportunity to assess how a Sartrean position (which makes use of some conceptual tools rooted in a different philosophical heritage) fares with regard to at least one particular set of concerns with which contemporary philosophers of mind take issue, namely, "On what basis are we entitled to attribute mentality/consciousness to others?"

In the first section I shall present Kirk's claims regarding Sartre's position on consciousness. Section II will be concerned with the manner in which Sartre tackles the problem of other minds in Being and Nothingness along with his and some of his critics' appraisals of the 
conclusions reached in that work. Sections III-IV offer my reconstruction of Sartre's text in view of supporting the contention that it is possible to make a strong case for Sartre's position on the matter. Finally, in sections V and VI I shall briefly present a few implications which can be drawn from my reconstruction of the Sartrean position for both the scientific study of consciousness and ethics respectively.

\section{Kirk's Criticism of the For-itself}

The main theme of Kirk's latest work has been to show the implausibility of the conception of the 'philosophical' zombie, that is:

[of creatures which] would both look and behave exactly like us. They would not be corpses but fully functioning human bodies, physically just like human beings down to the tiniest neurophysiological details. Yet by definition they would have no conscious experiences at all: there is supposed to be 'nothing it is like' to be a zombie. (Kirk, "Zapping the Zombies" 47)

The role which the zombie thought experiment has played in the literature is mainly that of advancing a case against physicalist views of consciousness. In particular:

if zombies are so much as possible, then there is more to human consciousness than can be accounted for in purely physical terms. If they are possible, we have non-physical components whose presence explains the fact that there is something it is like to be one of us; in which case the world is not a purely physical system. (47)

As Kirk sets out to assess other philosophers' theories of consciousness in the light of his own position, this is what he writes in relation to the Sartrean for-itself:

Sartre just takes it for granted that there are these special entities, these 'for-itselfs'... either Sartre is just a behaviorist - a position we have seen good reason to reject (and which he himself also rejects) — or he assumes there are no problems over explaining what it is for something to be a for-itself. Either way, he leaves the what-is-it problem untouched. (Kirk, Zombies and Consciousness 203) 
In Kirk's view, the 'what-is-it' problem consists in spelling out some necessary and sufficient conditions which are designed to warrant the attribution of consciousness to an entity from the second/third person perspective. His contention is that Sartre, while offering deep insights into human existence, does take the existence of conscious entities for granted. After all, how can Sartre be sure that the human characters he describes in Being and Nothingness are conscious beings and not, for instance, sophisticated robots or zombies? ${ }^{4}$

The focus of this paper is to provide a response to Kirk's conclusion, but first I shall consider Sartre's position and his assessment of it together with a critical overview of relevant works of Sartrean scholarship on the problem at hand.

\section{Sartre Against Himself}

A philosophy which takes its initial moves from the cogito such as Sartre's existential phenomenology, almost inevitably finds itself having to tackle the problem of other minds. Here the concern is not specifically that of having to prove whether consciousness is reducible to matter and the laws governing it—which figures centrally in contemporary debates in analytical philosophy of mind-but rather, the main task is to forestall the possibility of a shipwreck against the "reef of solipsism" (although Sartre's conclusions will have some implications regarding the nature of the relation between the physical and the psychical realms, which will be pointed out later in this paper). Sartre faces the problem of solipsism head-on in The Transcendence of the Ego. Here he reaches the conclusion that consciousness at its most basic level, its pre-reflective level, is egoless: it is an absolute transcendental field of immanence which thrusts itself in the world and at the same time makes an implicit, non-thetic reference to itself. The "I" and the "Me" are not the inhabitants of consciousness, but its products which lie 
outside of consciousness and are transcendent with respect to it. Consequently, it is Sartre's conviction that to the extent that the "I" and the "Me" are outside of consciousness-out there in the world-knowledge of them would not be more problematic from the second/third person perspective than it would be from the first-person perspective. Sartre writes:

I cannot conceive Peter's consciousness without making an object of it (since I do not conceive it as being my consciousness). I cannot conceive it because I would have to think of it as pure interiority and as transcendence at the same time, which is impossible. A consciousness cannot conceive of a consciousness other than itself. Thus we can distinguish, thanks to our conception of the me, a sphere accessible to psychology, in which the method of external observation and the introspective method have the same rights and can mutually assist each other, and a pure transcendental sphere accessible to phenomenology alone. (The Transcendence of the Ego 96)

And again:

This conception of the ego seems to us the only possible refutation of solipsism ... As long as the $I$ remains a structure of consciousness, it will always remain possible to oppose consciousness, with its $I$, to all other existents ... But if the $I$ becomes transcendent, it participates in all the vicissitudes of the world ... and solipsism becomes unthinkable from the moment the $I$ no longer has a privileged status. Instead of expressing itself in effect as 'I alone exist as absolute,' it must assert that 'absolute consciousness alone exists as absolute,' which is obviously a truism. My I, in effect is no more certain for consciousness than the I of other men. It is only more intimate. (103-104)

However, although the "I" and the "Me" are both public objects, hence open to observation both from the first-person and the second/third person perspective, the asymmetry between the two perspectives with respect to knowing whether consciousness is present is not thereby overcome.

In other words, Kirk's question regarding whether $\mathrm{X}$ is a person or a zombie can still plausibly be raised. In sum, solipsism has not been refuted. As Sartre later puts it:

Formerly I believed that I could escape solipsism by refuting Husserl's concept of the Transcendental 'Ego.' At that time I thought that since I had emptied my consciousness of its subject, nothing remained there which was privileged as compared to the Other. But actually although I am still persuaded that the hypothesis of a transcendental subject is useless and disastrous, abandoning it does not help one bit to solve the question of the existence of Others. Even if outside the empirical Ego there is nothing other than the consciousness of that Ego-that is, a transcendental field without a subject-the fact 
remains that my affirmation of the Other demands and requires the existence beyond the world of a similar transcendental field. (Being and Nothingness 235)

In his critical survey of some of his predecessors' approaches to the problem, Sartre claims that the existence of others has never been properly established mainly for the following two reasons: firstly, the relation between self and Other has been conceptualized in terms of external relation, which is the relation that holds between non-conscious entities:

At the origin of the problem of the existence of others, there is a fundamental presupposition: others are the Other, that is the self which is not myself ... The presupposition common to both idealism and realism is that the constituting negation is an external negation ... This is because the Other appears to me empirically on the occasion of the perception of a body, and this body is an in-itself external to my body; the type of relation which unites and separates these two bodies is a spatial relation, a relation of things which have no relation among themselves, pure exteriority in so far as it is given. $(230-231)$

Secondly, what has been at the forefront of philosophers' efforts was to establish the existence of other people on the grounds of knowledge rather than being. To the extent that this has been the case, then knowledge of other people has always failed to yield the Other as subject and has delivered the Other as object, whose existence as subject remains dubitable. As a consequence, both realist and idealist philosophers have ended up either in an untenable solipsism or in taking the Other as subject as a given. ${ }^{5}$

In what follows, it is clear that, contra Kirk, Sartre does not take the existence of other selves for granted; on the contrary, he continues to be acutely aware of it:

This woman whom I see coming toward me, this man who is passing by in the street, this beggar whom I hear calling before my window, all are for me objects. Thus it is true that at least one of the modalities of the Other's presence to me is object-ness. But we have seen that if this relation of object-ness is the fundamental relation between the Other and myself, then the Other's existence remains purely conjectural. Now it is not only conjectural but probable that this voice which I hear is that of a man and not a song on a phonograph; it is infinitely probable that the passerby whom I see is a man and not a perfected robot. (252253) 
However, in order to counter-act Kirk's remarks presented in the previous section, Sartre would have to produce a satisfactory answer to the problem.

Firstly, Sartre points out that the phenomenological apprehension of the Other as this particular man is not the same as apprehending an in-itself, e.g., a chair or a table in one's spatial field of action (254). However, this shows that we are dealing with an object of knowledge which "still retains a pure character of probability ... it is probable that this object is a man" (254). But this probability is a crucial clue: it is probable rather than conjectural that the passerby is a man rather than a robot. This highlights a hypothetical status whose claim to reality is quite strong thereby directing Sartre's inquiry into an ontologically more fundamental encounter with other people than our ordinary empirical dealings with them in the dimension of object-ness affords, that is, an encounter with the transcendental consciousness as Other upon which the encounter with the embodied other-as-object is grounded. Sartre makes clear that his project does not "offer a new proof of the existence of others, or an argument better than any other against solipsism" (250). However, far from implying that he takes the existence of others for granted, Sartre sets out to delve deeply into the strong resistance to solipsism that underlies our everyday interactions with other people (what he calls a "pre-ontological" comprehension of the existence of other people) by resorting to the phenomenologist's foothold on certainty, namely, the cogito:

If the Other's existence is not a vain conjecture, a pure fiction, this is because there is a sort of cogito concerning it. It is this cogito which we must bring to light by specifying its structures and determining its scope and its laws ... The cogito examined once again, must throw me outside it and onto the Other ... In my own inmost depths I must find not reasons for believing that the Other exists but the Other himself as not being me. (251)

Furthermore, the 'not' referred to in the last line of the above quotation is not to be understood as a judgment of non-identity of self and Other along the lines of what Sartre calls 'external 
negation,' that is, the kind of relation that holds among non-conscious entities, e.g., 'this chair is not this table.' In particular, Sartre has recourse to a notion of Hegelian provenance, which is central to his view of human reality: "This negation ... will be an internal negation, which means a synthetic, active connection of the two terms, each one of which constitutes itself by denying that it is the other" (252).

The cogito which ontologically grounds our ontic certainty of the existence of others is revealed through the well-known phenomenon of "the look" (le regard) on the occasion of the experience of shame. Sartre describes the radical modification of the cogito as the situation shifts from the situation-for-itself to its being-for-another consciousness; it is not a process, but a sudden, essential modification of the structure of the consciousness reflected-on:

Let us imagine that moved by jealousy, curiosity, or vice I have just glued my ear to the door and looked through a keyhole. I am alone and on the level of a non-thetic selfconsciousness. This means first of all that there is no self to inhabit my consciousness, nothing therefore to which I can refer my acts in order to qualify them. They are in no way known; I am my acts ... I am a pure consciousness of things ... I can not truly define myself as being in a situation: first because I am not a positional consciousness of myself; second because I am my own nothingness ... I can not even define myself as truly being in the process of listening at doors ... But all of a sudden I hear footsteps in the hall. Someone is looking at me! What does this mean? It means that I am suddenly affected in my being and that essential modifications appear in my structure-modifications that I can apprehend and fix conceptually by means of the reflective cogito. (259-260)

The essential modification of my cogito as it yields the for-others is that now my world escapes me towards another centre of reference in relation to which I am an object; a no-thing for myself now I am something — in the specifics of Sartre's example, I am ashamed in front of the Otherand the foundation of what I am does not lie in myself but in an Other. Furthermore, this Other has no face or bodily features for me: for me to be able to apprehend such features in the Other, the latter would have to be an object-for-me, rather, my encounter is with a pure transcendental gaze which is-not-Me. 
Sartre's approach to the problem of the existence of other minds succeeds in showing how my being is radically affected from the outside. However, does he succeed in establishing that the transcendental consciousness to which the radical modification of my cogito is attributed is a real existent in the world? After all it is conceivable that Sartre imagines that during his spying activity someone is coming down the hall. ${ }^{6}$ In this case, although the cogito could conceivably undergo the radical modifications which Sartre relates in his phenomenological description, no transcendental consciousness-as-Other would be present and the threat of solipsism would still seem to be very much alive. Such conclusion has in fact been commonly accepted by a number of critics and Sartre himself seems to have arrived at a less than satisfactory assessment of his own response to the problem of other minds. In Notebooks for an Ethics, a later work, Sartre writes:

But how can one unveil the Other as freedom? One can no doubt-and this comes firstgrasp the Other as a look. But this disquieting, undifferentiated, and intermittent freedom is not the freedom of this Other; it is the intuition of another freedom in general. (Notebooks 500)

A closely similar view is taken by Maurice Natanson:

[I]n searching for an account of myself-for-the-Other, I take for granted precisely the question at issue in this entire discussion: How is the concrete Other constituted as a fellow man? Not only has Sartre failed to answer the question concerning the concrete Other, he is incapable of answering it as long as he remains on the terrain of his ontology. ("Others" 336)

In regard to the above quotations from Sartre's and Natanson's texts, I confine myself to the following observation, at least at this stage in the exposition: according to Sartre's theoretical framework, it would be necessarily impossible to unveil the "extra-mundane being of the Other" (Being and Nothingness 234) together with this concrete other (e.g., Pierre or Annie) at the same time and through the same cogito. The two acts of consciousness required for this to be possible 
are essentially incompatible, as are the kinds of being which they are called forth to yield (i.e., the former being on the transcendental-ontological plane and the latter on the empirical-ontic plane). Sartre makes this explicit in the text. For example, he writes:

There is indeed a confusion here between two distinct orders of knowledge and two types of being which can not be compared ... then although I immediately experience and with certainty the fact of being-looked-at, I can not make this certainty pass into my experience of the Other-as-object ... Better yet, the look, as we have shown, appears on the ground of the destruction of the object which manifests it. (Being and Nothingness 276)

As I pointed out earlier in this section, Sartre's original project in Being and Nothingness connects with his acknowledged failure in The Transcendence of the Ego to establish the existence of the "transcendental field" in respect to which the "I" and the "Me" of the Other are the transcendent objects in the world. Thus, considering that a transcendental consciousness cannot, as a logico-ontological necessity, be apprehended as the empirical person (e.g., Pierre or Annie), if Sartre's approach succeeds in establishing with a priori certainty such transcendental field as another for-itself, it will have fulfilled its purpose. This does not exclude the necessity of having to relate that transcendental field to a concrete person, as long as it is recognized that such a task belongs with a separate project which calls forth a different structure of consciousness.

Leo Fretz also criticizes Sartre on account of not having succeeded in establishing the existence of a concrete person. Here, I would like to focus upon the following argument which he offers as a way of summarizing Sartre's position:

1. The existence of the Other is a necessary condition for my experience of shame.

2 . In the example given, I may well be in error with respect to the physical presence of the other. However, the experience of shame itself is evident and admits of no doubt.

3. Consequently, the other exists. ("Individuality" 87)

On the basis of the above, Fretz rightly concludes that Sartre's refutation of solipsism is not convincing since "it has become apparent that the apodictical evidence for the existence of the 
other is, in the last resort, based on the absence of such an other ... Precisely because the fundamental presence is manifest as an absence, it reinforces the solipsistical position" ("Individuality" 87). One might point out that the above argument possibly rests upon an equivocation between "existence" and "physical presence." On the face of it one might argue that 1. and 2. are self-contradictory: in fact if the existence of the Other is a necessary condition for my experience of shame, then unless the primary sense of "existence" that the argument is designed to establish is different from "physical presence," it cannot be admitted that the Other is not physically present if I am experiencing shame. Alternatively, 1. is not true, that is, it is only contingently that when I experience shame the Other is required. Neither of these readings implied by the analysis of Fretz's argument seem satisfactory. In fact, 1. is repeatedly affirmed by Sartre. ${ }^{7}$ Furthermore, as I shall show later in this paper, it constitutes a logically necessary element for the success of Sartre's approach. With regard to Fretz's reading of "existence" I do not think that Sartre would agree with equating "existence" with "absence" as he attempts to establish the existence of other selves. ${ }^{8}$ In particular, according to the Sartrean framework absence is indeed a way in which something can exist, but it is not selbständig. In regard to the specific problem at issue the following quotation leaves little doubt to the contrary:

For Pierre to be absent in relation to Thérèse is a particular way of his being present. In fact absence has meaning only if all the relations of Pierre with Thérèse are preserved: he loves her, he is her husband, he supports her, etc. In particular, absence supposes the maintenance of the concrete existence of Pierre: death is not an absence. (Being and Nothingness 278)

Absence, a form of negation, does always presuppose the presence of the being which is lacking or missing. More importantly, this holds for the foundation of all négatités, namely, the for-itself, which ontologically and logically presupposes the primacy of the in-itself, which is pure actuality. 
However, setting aside this point, I agree with Fretz on account of not finding Sartre's position as it stands in the text a satisfactory one. What I think does call for attention in Fretz's reconstruction is that the cogito seems to be inadequate as the sole ground for establishing the real being of another consciousness - a point which will be followed up as my argument progresses.

Another interesting way of looking at Sartre's proposed solution to the problem of other minds is offered by Peter Caws, who reaches the following conclusion:

The subjectivity of the Other is in such cases transcendent, in the sense that it does not appear in my world although it may profoundly modify the sense of that world ... 'The Other' is therefore a regulative concept, in Kant's sense, in that it confers intelligibility on the world, or at any rate produces in us a conviction of intelligibility on the ground that the world, however confusing to us, must have been organized by some other subjectivity. The concept is thus a very powerful one: on the one hand it extends to the idea of God, on the other it accounts for alienation. (Sartre 99-100)

Although I find the above view quite intriguing, I cannot rest satisfied with it. Firstly, if the Other were simply a regulative concept in Kant's sense, then for the same reason the project of establishing its existence would be misguided from the beginning. Namely: to do so would be beyond the limits of human beings' capacities; the most human beings could and ought to aspire towards would be to live as though the Other existed. Clearly in a way that does not seem to be congruent with Caws' interpretation at the cost of self-contradiction on Sartre's part, Sartre is convinced that his self-appointed task consists in bringing to light a relation "in which the Other must be given to me directly as a subject although in connection with me" (Being and Nothingness 253). Furthermore, in Being and Nothingness Sartre is convinced that he has succeeded in doing just that: "Thus through the look I experience the Other concretely as a free, conscious subject who causes there to be a world by temporalizing himself toward his own possibilities" (271). The Sartrean Other does much more than requiring rational assent to its 
existence in the manner of a regulative concept; it affects the self at the most fundamental level of its being.

Kathleen Wider's criticism of Sartre's account takes issue with the essentially conflictual nature of intersubjectivity. In her view, the latter is belied by scientific studies conducted in the last few decades on the ability of infants to imitate the facial expressions and gestures of adults. Wider does concede that the look of the Other may be dramatically alienating. However, she does not agree with Sartre in regard to the primacy of the alienating look. In this regard, she points to an earlier encounter in the form of "looking with" and "looking at" the Other which takes place in the imitative relationship of the infant with the adult. This is taken to be the source of self-discovery rather than self-alienation in which the Other is not experienced as object but as subject of action.

Wider's interpretation, although highly appealing, leaves itself open to the following objections. Firstly, I think Sartre might still argue that the sense in which "the look" is to be considered as being the primordial encounter with the Other-as-subject is not chronological; rather, it is ontological primacy that is crucial here. Sartre could even argue without selfcontradiction that "the look" could only be experienced by an empirical self which has already grown into a certain basic degree of socialization, which might very well take place according to the modalities uncovered by empirical studies. Wider is of the view that infant and adult do experience one another as subjects of action. However, the notion of "experiencing oneself or the other as subject or object" in our everyday life—be it our infant or adult experience-is not the same as that explicated by Sartrean phenomenology. For someone who does not adopt an explicitly phenomenological stance, Sartre points to such extra-ordinary phenomena as nausea or anguish as the only available options to pierce through the "circuit of selfness" in terms of which 
the world is ordinarily experienced. By bringing about a rupture with "everydayness," these can be identified as being truly ontologically revelatory. Hence rejecting Sartre's analysis by having recourse to empirical experience (be it ordinary experience or scientifically informed experience) misses the point. More specifically, Sartre's philosophy places itself on a different level with respect to the empirical plane. As a distinctively critical philosophy it does not take the deliverances of the empirical subject at face value, but aims to uncover the ontological conditions for an empirical world whose appearances commonly camouflage their real Being. It is a task for methodology, which Sartre makes explicit in his works, to indicate which kind of experience and which manner of approaching and comprehending that particular kind of experience could serve as vehicle for the adequate manifestation of the ontological realm. Secondly, with regard to Wider's reference to the findings of scientific research in particular, it is important to recall that from its early days phenomenology has been in an important respect motivated by deep dissatisfaction with the status of the positive sciences, especially with the lack of self-questioning in relation to the tacit assumptions underlying their methods and results (which does not imply that phenomenology is or logically must be anti-scientific). In addition, existential phenomenology, both in its Heideggerian and Sartrean conceptions, does take a firm stance with regard to the relationship between ontology and epistemology according to which the latter is to be grounded by an adequate ontology and not vice versa. Thus Sartre could still counter the results of scientific studies on intersubjectivity on account of their implicit ontological assumptions and their implications for a conception of human reality from a philosophical perspective.

Merleau-Ponty's criticism of the alienating look contains echoes of Heidegger's Mit-sein in its stress on the commonality of the intersubjective world which is revealed through the 
significance of implements. There is "one particular cultural object" to which Merleau-Ponty draws attention, that is, language and the experience of dialogue. The latter is in his view the fundamental relationship between self and Other. In this regard, he writes:

The other transforms me into an object and denies me, I transform him into an object and deny him, it is asserted. In fact the other's gaze transforms me into an object, and mine him, only if both of us withdraw into the core of our thinking nature, if we both make ourselves into an inhuman gaze, if each of us feels his actions to be not taken up and understood, but observed as if they were an insect's. This is what happens, for instance, when I fall under the gaze of a stranger. But even then, the objectification of each by the other's gaze is felt as unbearable only because it takes the place of possible communication. A dog's gaze directed towards me causes me no embarrassment. The refusal to communicate, however, is still a form of communication. (Phenomenology of Perception 360-361)

Merleau-Ponty here affirms the ontological primacy of communication over the alienating Sartrean look: communication is the default relationship between self and Other and it is on the "assumption of a community of men endowed with speech" that it is possible for me to "evolve a solipsist philosophy" (360). However, one might argue that Merleau-Ponty has not established how communication is my original relation with the Other. After all, communication assumes the subjectivity of the Other, it does not provide a philosophical argument for it. Moreover, as I have already mentioned, Sartre does acknowledge our strong resistance to solipsism as well as the futility of any project to escape or deny other people, which is necessarily parasitic on an implicit "givenness" of the existence of the latter. However, these phenomena are not ontologically fundamental for Sartre. On the contrary, they call for phenomenological investigation in their turn-an investigation which leads Sartre to delve deeply into a further structure of consciousness: the for-others. ${ }^{9}$

To conclude, to the extent that the existence of the Other is taken to have been apodictically established on the basis of the look, I partly agree with Fretz's conclusion 
according to which Sartre's proposal is unsatisfactory. However, in my view this is so not so much because Sartre fails to establish the existence of a concrete person (e.g., Pierre or Annie) but mainly because if the possibility that the phenomenon of being-looked-at, that is, the radical transformation of the cogito from a being-for-itself to a being-for-others, can be conceived as occurring in the absence of another subjectivity, then the cogito by itself although playing a central role in the project is not adequate to ground the existence of that subjectivity necessarily and beyond doubt. This possibility is also what constitutes the failure of Sartre's position in Ayer's view: "It may be certain that I have the feeling of being watched, and this may reasonably be taken to involve a belief on my part that other subjects exist. But what we require is a logical justification of this belief, and this, so far as I can see, Sartre makes no attempt to provide" ("Novelist-Philosophers" 106). ${ }^{10}$

In the following two sections I shall attempt to reconstruct an argument on the basis of Sartre's ontological work which attempts to provide the sort of strong justification of the existence of others to which Ayer appeals by complementing the results yielded by the cogito with the powerful logic of the transcendental argument.

\section{Sartre's Method}

Firstly, I shall present a few preliminary claims concerning my proposed reading of Sartre's methodology.

A significant number of pages in Being and Nothingness aim to show how the view of consciousness in terms of a reified inner psychic object and the concept of the mechanicalinstrumental body do arise in the dimension of what in phenomenological parlance is known as the "natural attitude," to which belong both our ordinary empirical experience and the positive 
sciences. Sartre elaborates a framework along the lines of a revised version of the Kantian critical tradition which does provide the theoretical tools necessary to account for and thus overcome the dichotomy (e.g. between "inner" and "outer," consciousness and body) to which the natural attitude gives rise.

I propose the following reading of Sartre's phenomenologico-ontological method. Sartre describes a type of conduct which others would readily recognize. Subsequently, Sartre poses a transcendental question of the Kantian type regarding the a priori conditions of possibility for the conduct thus described. In my view, it is not crucial that when the description involves a "what it is like" aspect then it must necessarily be assumed that this is what it is like for all people when they perform a similar kind of action (although one might say that Sartre does expect as much from his readers). For the method to work, it would be sufficient that others recognize the phenomenon as a human phenomenon, that is, as a type of conduct that themselves and others might very well adopt in their life. In my view, this is so, because the descriptions do not by themselves carry the work's appointed philosophical task of establishing an ontology of consciousness. It is their being as real possibles in a human world which acquires centrality here in that it is made to function as premise for the transcendental argument in view of establishing the a priori necessary conditions for their possibility (i.e., certain conscious structures).

The praxis-oriented approach allows us to view consciousness as a material structure in the world, not as an inward phenomenon. Furthermore, it is not any material structure whatsoever but the doer or agent him/herself, and since Sartre is focusing upon the realm of action, it cannot be otherwise.

Finally, the transcendental turn allows us to grasp just the limits of our experience as humans. Doing so affords the opportunity of establishing the necessary conditions of possibility 
for there to be a point of view. If phenomenology is traditionally intended as an exclusively firstperson methodology — which by and large it is - then this reading of Sartre's work could be taken as widening phenomenology's scope and power of comprehension. Sartre's words in this regard are revealing: "In truth the cogito must be our point of departure, but we can say of it ... that it leads us only on condition that we get out of it" (Being and Nothingness 73-74).

\section{Consciousness and Body: Philosophical Grounds}

From the pages of Being and Nothingness it is possible to extrapolate two routes towards establishing that conscious matter has an outside or, better still, that consciousness exists asoutside, thus further showing that Sartre remains consistent in his project of overcoming the inner-outer dichotomy. In fact, he establishes consciousness-as-outside both from the first person perspective (as one would commonly expect from a traditionally phenomenological approach) and from the second/third person perspective. Accordingly, it might be safe to claim that in establishing an essential structure of conscious matter it must be possible to do so from both first

and second/third person perspectives, at least if the dichotomy between the perspectives is that against which one is arguing.

Establishing consciousness-as-outside from the second/third person perspective takes priority over doing so from the first person perspective, both in the order of presentation in Being and Nothingness and, in my view, as a logical requirement. Namely: we need to be in possession of what the second/third person inquiry yields before we are justified in drawing the conclusions that we wish to draw from the first person approach. Why this is so will become clear in the course of my exposition. 


\section{A. Second/Third Person Perspective: Bad Faith}

As I showed earlier in this paper, Sartre's approach to the problem of the existence of others, as well as the scholarly debates to which it has given rise, have focused on part three, chapter one of Being and Nothingness in which Sartre brings forth the structure of the for-others through the phenomenon of the look. However, in order to provide a cogent argument, that is, an argument which succeeds in establishing the existence of other conscious beings with the force of a priori necessity, I shall reconstruct Sartre's view starting from an earlier section, namely, part one, chapter two: "Bad Faith."

Interestingly, the cases of bad faith which Sartre highlights in Being and Nothingness, namely, the woman who goes out with a man for the first time, the café waiter, and the intersubjective situation between the homosexual and the champion of sincerity, are all described from an outside perspective, that is, they are what the cogito delivers to the phenomenologist concerning the conduct of an Other (not concerning the phenomenologist's conduct).

Right away Sartre places himself already both inside and outside the cogito to the extent that, although revealed through the phenomenologist's reflection, conduct is i) a public, praxisinformed event of an Other in the world, and ii) it develops in time; both i) and ii) allow for a description of that type of conduct which in its turn lends itself to being shared with others, hence to being part of an intersubjective dialogue. Further, conduct, unlike behavior, conceptually includes consciousness. For example, without being a café waiter himself, Sartre delivers recognizable descriptions of the waiter's conduct both as the waiter appears from the outside and as the waiter's situation is for-him, that is, from the inside (59-60). However, the question might still arise as to whether there is a human being out there to whom Sartre's description of the waiter does apply or what in fact looks like a waiter is only an automaton or 
sophisticated zombie. In other words, does Sartre simply assume-as Kirk claims - that there is an inside to the waiter's outward behavior?

The crucial step in answering this question consists in articulating the transcendental question taking bad faith conduct as its basic premise: "What must be the being of [those particular beings] if [they are] to be capable of bad faith?" (55). ${ }^{11}$

Sartre's deduction yields the following conclusion: "Negation has referred us to freedom, freedom to bad faith, and bad faith to the being of consciousness, which is the requisite condition for the possibility of bad faith" (73). Better yet, the result of the deduction consists in a specific structure of conscious matter and no other: "The condition of the possibility for bad faith is that human reality, in its most immediate being, in the intra-structure of the pre-reflective cogito, must be what it is not and not be what it is" $(67) .{ }^{12}$

The above definition, whose layers are painstakingly unpacked in Being and Nothingness, indicates that consciousness is itself a perspectival mode of being: not only is the world revealed to us through limited perspectives, and we are revealed to ourselves and others through limited perspectives (hence also our empirical apprehension of consciousness takes place through limited perspectives), but consciousness, the source of all perspective, is itself perspectival and relational. In particular, at its fundamental, hence pre-reflective level, i) conscious matter is a being-for-itself and a being-for-others, and ii) the inter-relation between perspectives and the intra-relation within each perspective is an internal relation of noncoincidence of conscious matter with itself, as both facticity (i.e., physical givens, psychic contents, the sedimentation of past experience) and transcendence towards what is beyond itself (i.e., future self, the world, and others). The notion escapes the logic of self-identity but it is not 
to be considered as dichotomous; rather, it is authentically dialectical: it is a unity in difference, a nihilating synthetic relation between essentially non-coincident perspectives. ${ }^{13}$

To summarize: the conclusion of Sartre's enquiry that is relevant to my argument is twofold. In particular, conscious matter is essentially, at its pre-positional fundamental level, perspectival and relational; it is at the same time for-itself, that is, it is a first person perspective, and a for-others, that is, it is a being-for a second/third person perspective; further, the relation between the perspectives is a dialectical one of self-nihilating internal synthesis. According to this reading, the body is not an indirect route to or an index of what might be going on inside the skull. Rather, it is a manifestation of consciousness (i.e., consciousness as internal relation to its facticity). In other words, Sartre transcendentally establishes that the 'outside' is an essential structure of conscious matter. ${ }^{14}$

Let us now turn to the second route which is designed to lead us to the same conclusion about consciousness, that is, the first-person, cogito-based route.

\section{B. First Person Perspective: Shame}

Earlier discussion of the Sartrean look in this paper has led to the conclusion that the cogito by itself fails to deliver a satisfactory solution to the problem of other minds. However, here I would like to point to a different—in my view, more fruitful-reading of Sartre's enterprise in relation to his notion of the look.

In particular, I would argue that the Sartrean look is not to be understood in the first instance as establishing the existence of the Other-as-subject. Rather, Sartre's strategy through the notion of the look would be more aptly read as establishing one's being-for-others, that is, 
one's own conscious matter as-outside, from the first-person perspective and on this premise transcendentally deducing the existence of the Other-as-subject.

In fact, what is revealed to me through the look is an essentially different relation with the being that I am, a relationship whose centre of reference is not me and which escapes me, it is my being which is revealed to myself but as it is for an Other: I am from the outside, as it were. Hartmann conveys this reading quite strongly as follows: "The object-Me is my limit, and as such not ideal but real: this being-for-others is my body" (Sartre's Ontology 118, emphasis added). This is the premise for the transcendental question: "What is the necessary condition for the possibility of my first-person revelation of my being-for-others?" The answer would be: "The existence of the Other-as-subject." In Sartre's words: "If someone looks at me, I am conscious of being an object. But this consciousness can be produced only in and through the existence of the Other" (Being and Nothingness 271).

This is the reason why the argument advanced in the previous subsection in view of establishing the conscious being of the other-as-object through the phenomenon of bad faith has logical priority: it is on the basis of the results yielded by that argument that Sartre would be philosophically entitled to claim-independently of the cogito delivered through the look-that the internal relation of consciousness as for-itself, by necessity of its nature, cannot objectify itself (although its being as lack manifests itself as a desire for self-objectification). Consequently, the Other-as-subject is transcendentally necessary for my first-person revelation of my being-for-others to be possible. ${ }^{15}$

This move provides a viable solution to the problem of the "absent Other" as being equally equipped to bring about the cogito of the for-others as the "present Other," which was highlighted in section II above. In fact, on the reading offered here it is only on the basis of a 
primordial real encounter with the Other-as-subject that mistakes as to its presence on particular occasions might plausibly be thought to occur.

Finally, as a way of consolidating my conclusions it is important to note that, although it is a matter of contingency that others do in fact exist (hence that it is not a priori necessary for me to become aware of my being-for-others) it is not a matter of contingency that I, as conscious being, am a being-for-others, that is, that I am consciousness-as-outside- $\mathrm{I}$ am, in Sartre's words, "my being-outside" [mon dehors] (Being and Nothingness 286).

\section{Implications For Consciousness Studies}

In the foregoing sections I have attempted to counter Kirk's claim according to which Sartre does take for granted that other people are conscious. The twofold second/third person and first person argument for the existence of consciousness-as-outside is a powerful counterpoint to Kirk's necessary and sufficient conditions for the correct application of the concept of consciousness to other entities. In particular, it succeeds in firmly establishing that consciousness, as both inside and outside, is a priori required if certain types of overtly recognizable conduct are to be possible.

Kirk's aim in elaborating his view of the external conditions for the existence of conscious beings is ultimately that of providing scientists with a concept of consciousness which is amenable to scientific investigation. In particular, by resorting to the concepts offered by Kirk, the scientist would be logically entitled to investigate neurobiological and behavioral phenomena without having to concern herself with theoretical questions as to whether consciousness could exist independently of those phenomena—a possibility which would have left her scientific 
investigations open to the criticism of failing to purport any significant bearing upon conscious structures and operations.

At this point, the following question might arise: does Sartre's phenomenologicotranscendental view of consciousness-as-body (or as-outside) allow for a scientific approach to consciousness? My view is that it would not necessarily rule out such approach. However, it is to be made clear that the identity between bodily events and functions on the one hand, and conscious structures on the other, cannot of necessity be cognitively available to us on the empirical plane of scientific investigation. Sartre explicitly states as much: "psycho-physical identity can only be established ontologically, as Spinoza acknowledged" (Being and Nothingness 87). It is only on the ontological, that is, the transcendental plane rather than the ontic, empirical realm, that it is possible to make sense of and intelligibly account for the unity of body and consciousness.

The upshot of this for the present discussion is that scientific investigations of consciousness can be accommodated within a Sartrean framework so long as we are clear on the following point: if, using Sartrean terminology, we consider this kind of study in its proper order of being and of knowledge (as indeed we should) what the scientist would be studying would not be the nature of consciousness simpliciter. Rather, the scientist would have access to an alienated consciousness, that is, an empirical consciousness whose phenomenal features do depend upon varying degrees of objectification which take place through complex intra- and inter-relating conscious perspectives and the restructuring work of language. A Sartrean approach does enable us theoretically to account for views of consciousness which the empirical psychologist and the neurobiologist would countenance, although not by way of the transcendental deduction. This, however, is not only acceptable, but also logically required by the present argument: to the extent 
that the empirical psychologist's or the neurobiologist's models of consciousness do not capture fundamental structures of consciousness, then they necessarily fail to meet the requirements of the transcendental deduction. Their appropriate place in the Sartrean framework is among what Sartre refers to as "aberrant type of appearance" (Being and Nothingness 357). Such kind of appearance, depending upon the degrees of objectification and reification out of which it has arisen, ranges from the dimension of the "psychic object" $(330-333,354)$ to that of the "body [viewed] in terms of the corpse" $(348,350)$.

\section{Implications For Ethics}

The present discussion contains some implications regarding the treatment of oneself and others. ${ }^{17}$ What I would like to emphasize is that a closer look at Sartre's text affords a fresh philosophical understanding of conscious being. This does enable us to go beyond the dichotomy between the scientist's view according to which consciousness is a ghostly byproduct of causal laws of motion and neurobiological functions, and, on the other hand, the Cartesian-minded philosopher's view according to which the body is the passive, at most expressive, instrument or container of the autonomous conscious subject.

According to a Sartrean position, bodily/natural features in the existential dimension of facticity, as well as first-person subjectivity, are intrinsic, essential structures of conscious being at its fundamental level of existence. Sartre's phenomenologico-transcendental framework enables us, among other things, theoretically to ground the familiar insight that great care, moral reflection and sensitivity are called for when exercising scientific practice (i.e., experiments in general and clinical experiments in particular) and applying scientific knowledge by means of technology (e.g., genetic engineering, polygraph machines) upon conscious beings.* 


\section{Notes}

* This is a revised version of a paper presented at the $13^{\text {th }}$ Annual Conference of the UK Society for Sartrean Studies, which was held in October 2006 at the Institut français in London. I thank the Conference organizers, Dr. David Drake and Dr. Benedict O'Donohoe, and those present at the event for their thought-provoking questions. Also, I am extremely grateful to two anonymous referees of PhaenEx for their helpful comments.

1 Some invaluable contributions have been produced in which the dialogue of mainstream scientifico-philosophical work on mind and consciousness with the phenomenological tradition is most fruitful. See for example Gallagher and Zahavi, The Phenomenological Mind; Varela, Thompson and Rosch, The Embodied Mind; Petitot, Varela, Pachoud and Roy, Naturalizing Phenomenology, to name just a few.

${ }^{2}$ Kirk does not focus his work on Sartre's text. Rather, he offers a critical survey of alternative approaches to the problem of other minds among which he includes the Sartrean one. Kirk confines his remarks to Sartre's position, which he discusses together with Wittgenstein's, to half a page in Zombies and Consciousness and in Mind \& Body. However, this might be sufficient in my view to open up a dialogue and bring Sartre once more into the arena of contemporary debates in the philosophy of mind.

${ }^{3}$ A fine bibliography of scholarly work is available which testifies to the excellent work being done towards making a dialogue between Sartre and contemporary work in the philosophy of mind and related fields of psychology and the neurosciences possible. For example, see the superb work by Wider, The Bodily Nature of Consciousness: Sartre and Contemporary Philosophy of Mind; Catalano Thinking Matter; Barnes "Consciousness and Digestion: Sartre and Neuroscience"; Rowland Externalism; and Kreuger "Concrete Consciousness." My intervention in this paper is strictly circumscribed to the specific problem of other minds. Furthermore, to the extent that my approach does engage with the dialogue between Sartre on the one hand and contemporary philosophy of mind and related neuroscientific studies of consciousness on the other, this is done in a critical vein with respect to the latter and by keeping rigorously to Sartre's specific philosophical perspective and conceptual framework. In this regard I acknowledge the deep influence of Catalano's work.

${ }^{4}$ Similarly, in Mind \& Body Kirk writes: "What concerns us is anything [Sartre] might have to contribute towards explaining what it is for there to be conscious systems in the first place. Unfortunately he is not focused on that question. He just takes for granted that there are these special entities, these 'for-itselfs.' Now, he rejects behaviorism ... So perhaps he assumes either that there is no problem over what it takes for something to be a for-itself, or that he doesn't need to tackle the problem" (163). As it will become clear throughout this paper, Sartre does all but assume that there is no problem of what it is for there to be conscious systems let alone that he does not need to tackle it: his struggle with the problem permeates a significant portion of his phenomenological ontology.

${ }^{5}$ See especially Being and Nothingness 229-232. 
${ }^{6}$ Sartre acknowledges this eventuality in Being and Nothingness 275-276.

${ }^{7}$ For example: "When I am alone, I can not realize my 'being-seated' ... But in order for me to be what I am, it suffices merely that the Other look at me ... I myself shall never succeed at realizing this 'being-seated' which I grasp in the Other's look. I shall remain forever a consciousness. But it is for the Other ... This is accomplished, not by any distortion or by a refraction which the Other would impose on my transcendence through his categories, but by his very being" (Being and Nothingness 262-263). And again: "the Other's look as the necessary condition of my objectivity is the destruction of all objectivity for me" (269). Also: "by fixing my possibilities the Other reveals to me the impossibility of my being an object except for another freedom. I can not be an object for myself ... thrown back on its own resources, the reflective effort towards a dissociation results in failure ... In experiencing the look, in experiencing myself as an unrevealed object-ness, I experience the inapprehensible subjectivity of the Other directly and with my being" (270).

${ }^{8}$ Hartmann also accepts this reading: "Sartre's solution of the problem is most peculiar. The objectification of me by the Other is no error for I remain affected by the Other in any case ... The Other may in fact be absent. Absence is a "particular way of ... being present'" (Sartre's Ontology 112).

${ }^{9}$ I do agree with the criticism brought to bear on Merleau-Ponty's phenomenological project by Hammond, Howarth and Keat according to which Merleau-Ponty ought to have made explicit the structures of the reflecting consciousness, which is what Husserl and Sartre did in their work. Failing to do so and concentrating only on the standpoint of embodied subjectivity leaves open the question of justifying the phenomenologist's conclusions. In particular: "There are two aspects to the self. There is the pre-logical bodily self; and there is the reflecting self, which describes the bodily self. Merleau-Ponty attends mainly to the former ... There is surely a need to examine the presuppositions of the philosophical reflector ... There is a standpoint from which one describes the pre-logical experience" (Understanding Phenomenology 269). I contend that this lack of questioning into the presuppositions of the phenomenological deliverances of the pre-logical bodily self is also at play in Merleau-Ponty's conclusions regarding inter-subjectivity.

10 Ayer's quotation is from "Novelist - Philosophers: Jean-Paul Sartre." Horizon 12, no. 67 (1945). Cited in Fretz, "Individuality," fn. 30, 98.

${ }^{11}$ It might be rightly objected that Sartre merely posits the phenomenon of bad faith and that consequently the possibility of such phenomenon could not be taken as constituting the premise for an argument without falling into circularity. However, I would like to point out that, although such premise is far from being a trivially self-evident proposition or a tautological analytical proposition, the premise is not for this reason simply posited; its choice has been justified in the previous section of the present paper on the basis of Sartre's detailed descriptions being recognizable as real (not simply logical) possibilities of human reality. Hence, only if it is argued that it is not only logically but also factually impossible for someone to act in bad faith after the manner of the café waiter, the woman out on a date, the homosexual, etc., then the transcendental 
argument here proposed could not get started. I thank one anonymous referee of PhaenEx for having pointed out this objection.

${ }^{12}$ An extensive literature dedicated to the analysis of Sartrean bad faith is available, which seems to point to the conclusion that the Sartrean cogito in its translucency is unable by itself to account for the phenomenon of bad faith. According to these readings of Sartrean bad faith the interplay between conscious and unconscious (or pre-conscious) psychic forces, in a way which presupposes the internalization of the Other, is required if a plausible account is to be offered. Sartre offers convincing reasons as to why an explanation of bad faith in such terms would only shift the difficulties onto the relationship between the psychic entities involved without solving the paradoxical character of the phenomenon itself. However, he leaves the matter unsolved. His position seems to be as follows: bad faith defies explanation but this does not need to detain us any further simply because people can undeniably be and most people actually are in bad faith; as long as the presence of the phenomenon is admitted we can draw the conclusions which we intend to draw from it and proceed with our inquiry. I do not agree with this conclusion: so much in Sartre's ontology hinges on such phenomenon in terms of the role which it plays in the explication of the structures of consciousness hence it would be a damaging lacuna in Sartre's framework to leave the matter unresolved. In relation to the argument at hand the consequences of such an objection would be disastrous: if the cogito cannot by its very nature carry out the project of bad faith then the transcendental argument presented in the main text has failed. Fortunately, this need not be the case. Elsewhere I offered a plausible account of bad faith. Without going into the details, here is a brief outline. My starting point has consisted in keeping bad faith and self-deception radically distinct: the former is best understood in terms of a project of consciousness which is located on the ontological plane of Being. The latter, with which the idea of lying to oneself or hiding something from oneself, which has ushered in the necessity for the internalization of the Other, has most naturally been associated, is to be understood as belonging with everyday empirical consciousness as only one among the various phenomenal manifestations of the Weltanschauung of bad faith. Further, the project of bad faith at the ontological level does provide the a priori conditions of possibility for the Weltanschauung of bad faith on the ontic plane. The crucial point in the argument is the following: I articulate the project of bad faith as consisting not so much in consciousness negating the being of either its transcendence or its facticity to itself, but in consciousness negating the value of either its transcendence or its facticity, which it is absolutely free to do without the need to posit any extraneous structure nor of hiding from itself the side of itself which it chooses to devalue. Such project on the ontological plane is then phenomenally given as the Weltanschauung of bad faith on the empirical, ontic plane where either consciousness' transcendence or its facticity are played down and the world reflects back to consciousness the image that it has put into it as either pure transcendence or passive facticity. It is important to recall that in Sartre's view, on the ontic plane consciousness is opaque to itself, that is, its ontological project is not directly accessible to it; clearly, once the project has been carried out ontologically, ontically "the chips are down." For a detailed discussion of this proposal and a critical survey of the secondary literature, see my "Bad-faith and Self-deception: Reconstructing the Sartrean Perspective."

13 The dialectical notion of unity in difference sits uncomfortably with the logic of analytic philosophy and it is one of those points where Wider's penetrating research into Sartre 
encounters a few interpretative difficulties. For instance: "[Conscious belief] is and is not what it is. Belief is belief but because it is self-conscious it is not belief" ("Through the Looking Glass" 334). In this regard, Wider admits that she fails "to see how it follows from the fact that selfawareness is a property of pre-reflective consciousness that an act of consciousness at the prereflective level, such as belief, is not itself" (336). This, however, is not to say that Sartre's text does not raise a few issues in this regard; on the contrary, I think that Wider's analysis has brought out some areas of Sartrean ontology worthy of a separate discussion.

${ }^{14}$ In regard to the relationship between consciousness and body Wider writes: "it is the body, the organism as a whole, that is conscious" (The Bodily Nature of Consciousness 114, emphasis added). To the extent that Wider relates consciousness to the whole body thereby distinguishing her position from the narrow concept of consciousness in terms of a property of a state or process of the brain which is prevalent in much, although not all, debates in the philosophy of mind, I am extremely sympathetic to her views. However, the position which I maintain in this paper is stronger than hers. Keeping in mind the dialectical sense of "is" which applies to an ontologically informed notion of consciousness, my conclusion is that the body is consciousnessas-outside.

15 The reading offered here seems to be quite close to what Sartre had in mind but did not fully articulate. In fact, his description of the self looking through the keyhole before the Other makes its dramatic entrance runs as follows: "since I am what I am not and since I am not what I am-I can not even define myself as truly being in the process of listening at doors. I escape this provisional definition of myself by means of all my transcendence. There as we have seen is the origin of bad faith" (Being and Nothingness 260). Thus, bad faith has enabled Sartre to explicate the being-for-itself of consciousness, which in its turn has equipped Sartre with the theoretical tools that entitle him to claim that the for-itself is necessarily (in the sense of ontological necessity) unable to be an object-for-itself.

${ }^{16}$ Here I clarify that I do not mean that consciousness-as-outside is in itself a bearer of moral value. Sartrean ontological structures of consciousness are sources of value but are themselves intrinsically value-neutral. Whether those ontological structures afford us the possibility of providing the ground for an ethics has been, and still is, a much debated topic among Sartre scholars. I discuss some aspects of this issue in "Spinozean Multitude" and offer a comprehensive and detailed account of a Sartrean ethics in Jean-Paul Sartre's Ethics of Authenticity.

\section{Works Cited}

Barnes, Hazel. "Consciousness and Digestion: Sartre and Neuroscience." Sartre Studies International 11, no. 1-2 (2005): 117-132.

Catalano, Joseph. Thinking Matter. New York and London: Routledge, 2000. 
Caws, Peter. Sartre. London, Boston, Melbourne and Henley: Routledge \& Kegan Paul, 1984.

Fretz, Leo. "Individuality in Sartre's Philosophy." The Cambridge Companion to Sartre. Ed. Christina Howells. Cambridge: Cambridge University Press, 1992. 67-99.

Gallagher, Shaun and Dan Zahavi. The Phenomenological Mind: An Introduction to Philosophy of Mind and Cognitive Science. London and New York: Routledge, 2007.

Hammond, Michael, Jane Howarth and Russell Keat. Understanding Phenomenology. Oxford UK and Cambridge USA: Blackwell, 1991.

Hartmann, Klaus. Sartre's Ontology: A Study of Being and Nothingness in the Light of Hegel's Logic. Evanston: Northwestern University Press, 1966.

Kirk, Robert. Zombies and Consciousness. Oxford: Oxford University Press, 2005.

—. Mind and Body. Chesham, Bucks: Acumen, 2003.

—. "Zapping the Zombies." Think 13 (2006): 47-58.

Krueger, Joel W. "Concrete Consciousness: A Sartrean Critique of Functionalist Accounts of Mind." Sartre Studies International 12, no.2 (2006): 44-60.

Merleau-Ponty, Maurice. Phenomenology of Perception. Trans. Colin Smith. London and New York: Routledge, 1995.

Natanson, Maurice. "The Problem of Others in Being and Nothingness." The Philosophy of JeanPaul Sartre. Ed. Paul Arthur Schlipp. La Salle, Illinois: Open Court, 1981. 326-344.

Perna, Maria Antonietta. "Bad Faith and Self-Deception: Reconstructing the Sartrean Perspective." The Journal of the British Society for Phenomenology 34, no. 1 (2003): 2244.

—. "Spinozean Multitude: Radical Italian Thought vis à vis Sartrean Existential Marxism." Sartre Studies International 13, no. 1 (2007): 35-61.

-. Jean-Paul Sartre's Ethics of Authenticity: An Analysis and Defense. Ph.D. dissertation. Birkbeck College, University of London, 1999.

Petitot, Jean, Francisco J. Varela, Bernard Pachoud and Jean-Michel Roy (eds.). Naturalizing Phenomenology: Issues in Contemporary Phenomenology and Cognitive Science. Stanford: Stanford University Press, 1999.

Rowlands, Mark. Externalism: Putting Mind and World Back Together Again. Ithaca: McGill Queen's University Press, 2003. 
Sartre, Jean-Paul. The Transcendence of the Ego: An Existentialist Theory of Consciousness. Trans. F. Williams and R. Kirkpatrick. New York: Hill and Wang, 1995.

—. Being and Nothingness: An Essay in Phenomenological Ontology. Trans. Hazel Barnes. London: Routledge, 1993.

-. Notebooks for an Ethics. Trans. D. Pellauer. Chicago: The University of Chicago Press, 1992.

Varela, Francisco, Evan Thompson and Eleanor Rosch. The Embodied Mind: Cognitive Science and Human Experience. Cambridge, Massachusetts: MIT Press, 1992.

Wider, Kathleen. The Bodily Nature of Consciousness: Sartre and Contemporary Philosophy of Mind. Ithaca: Cornell University Press, 1997.

—. "Through the Looking Glass: Sartre on Knowledge and the Pre-reflective Cogito." Man and World 22 (1989): 329-343.

-. "The Self and Others: Imitation in Infants and Sartre's Analysis of the Look." Continental Philosophy Review 32, no. 2 (1999): 195-210. 